\title{
Daedalus and Gasz recruit Armitage to mitochondria, bringing piRNA precursors to the biogenesis machinery
}

\author{
Marzia Munafò, Vera Manelli, Federica A. Falconio, Ashley Sawle, Emma Kneuss, Evelyn L. Eastwood, \\ Jun Wen Eugene Seah, Benjamin Czech, and Gregory J. Hannon \\ Cancer Research UK Cambridge Institute, Li Ka Shing Centre, University of Cambridge, Cambridge CB2 ORE, United Kingdom
}

The Piwi-interacting RNA (piRNA) pathway is a small RNA-based immune system that silences mobile genetic elements in animal germlines. piRNA biogenesis requires a specialized machinery that converts long singlestranded precursors into small RNAs of $\sim 25$-nucleotides in length. This process involves factors that operate in two different subcellular compartments: the nuage/Yb body and mitochondria. How these two sites communicate to achieve accurate substrate selection and efficient processing remains unclear. Here, we investigate a previously uncharacterized piRNA biogenesis factor, Daedalus (Daed), that is located on the outer mitochondrial membrane. Daed is essential for Zucchini-mediated piRNA production and the correct localization of the indispensable piRNA biogenesis factor Armitage (Armi). We found that Gasz and Daed interact with each other and likely provide a mitochondrial "anchoring platform" to ensure that Armi is held in place, proximal to Zucchini, during piRNA processing. Our data suggest that Armi initially identifies piRNA precursors in nuage/Yb bodies in a manner that depends on Piwi and then moves to mitochondria to present precursors to the mitochondrial biogenesis machinery. These results represent a significant step in understanding a critical aspect of transposon silencing; namely, how RNAs are chosen to instruct the piRNA machinery in the nature of its silencing targets.

[Keywords: Drosophila; ovary; PIWI proteins; transposon; mitochondria; piRNA biogenesis]

Supplemental material is available for this article.

Received February 18, 2019; revised version accepted April 16, 2019.

The Piwi-interacting RNA (piRNA) pathway acts in the germlines of animals as diverse as arthropods, amphibians, and mammals to control the expression of mobile genetic elements, protecting the genome from the potentially harmful consequences of uncontrolled transposon mobilization (Czech et al. 2018; Ozata et al. 2019). piRNAs function in complex with Argonaute proteins of the PIWI clade (in Drosophila, Piwi, Aubergine [Aub], and Argonaute-3 [Ago3]), guiding them to repress transposons at both transcriptional and posttranscriptional levels (Brennecke et al. 2007; Gunawardane et al. 2007; Sienski et al. 2012; Le Thomas et al. 2013; Rozhkov et al. 2013; Czech et al. 2018). This pathway has been studied extensively in Drosophila, where a number of genetic screens have uncovered many of its key components, some of which still await functional characterization (Czech et al. 2013; Handler et al. 2013; Muerdter et al. 2013).

Animal germ cells harbor characteristic perinuclear structures that are required for the production of piRNAs.

Corresponding authors: greg.hannon@cruk.cam.ac.uk, benjamin.czech@ cruk.cam.ac.uk

Article published online ahead of print. Article and publication date are online at http://www.genesdev.org/cgi/doi/10.1101/gad.325662.119. Freely available online through the Genes \& Development Open Access option.
In Drosophila nurse cells, these are called nuage and are the location where Aub/Ago3 ping-pong looping occurs (Brennecke et al. 2007; Gunawardane et al. 2007; Lim and Kai 2007; Malone et al. 2009). In follicle cells, piRNA precursors and biogenesis factors are concentrated in $\mathrm{Yb}$ bodies, named after their main component, female sterile (1) $\mathrm{Yb}(\mathrm{Yb})$ (Szakmary et al. 2009; Olivieri et al. 2010; Saito et al. 2010; Qi et al. 2011; Murota et al. 2014). Germline piRNA biogenesis begins in nuage with the generation of $5^{\prime}$ monophosphorylated $\left(5^{\prime}-\mathrm{P}\right)$ precursor RNAs via Aub/Ago3 slicing, a crucial event that specifies a cellular RNA as substrate for piRNA production (Han et al. 2015; Mohn et al. 2015; Senti et al. 2015; Wang et al. 2015; Gainetdinov et al. 2018). It is likely that a similar $5^{\prime}$-P precursor is generated without Aub or Ago3 in Yb bodies, but the underlying molecular mechanism for this process remains obscure. Following this initial precursor specification, the production of mature Piwi-bound piRNAs occurs on the outer surface of mitochondria, where the conserved endonuclease Zucchini (Zuc) converts single-stranded

(C) 2019 Munafò et al. This article, published in Genes \& Development, is available under a Creative Commons License (Attribution 4.0 International), as described at http://creativecommons.org/licenses/by/4.0/. 
5'-P precursor RNAs into strings of consecutive piRNAs, each 25 nucleotides (nt) in length (Ipsaro et al. 2012; Nishimasu et al. 2012; Han et al. 2015; Homolka et al. 2015; Mohn et al. 2015). During this process, binding of PIWI proteins to the $5^{\prime}-\mathrm{P}$ ends of the precursor RNAs is thought to help position Zuc, thus dictating the distinctive "phasing" of its cleavage (Gainetdinov et al. 2018). In essence, the PIWI footprint on the nascent piRNA precursor determines the $5^{\prime}$ end of the next piRNA in this processive cycle. Interestingly, the mitochondrial localization of the piRNA biogenesis machinery is generally conserved across species, strongly implying a functional role for mitochondria in piRNA biology and transposon defense.

Several other piRNA biogenesis factors are also localized to mitochondria, including the Tudor domaincontaining partner of PIWIs (Papi), the glycerol-3-phosphate acyltransferase Minotaur (Mino), and Gasz (the germ cell protein with Ankyrin repeats, sterile a motif [SAM], and leucine zipper) (Liu et al. 2011; Czech et al. 2013; Handler et al. 2013; Vagin et al. 2013; Hayashi et al. 2016). With the exception of Papi, which is largely dispensable in flies but is involved in piRNA $3^{\prime}$ formation in other species (Honda et al. 2013; Hayashi et al. 2016; Nishida et al. 2018), loss of any of these factors severely impairs Zuc-mediated piRNA generation. Compromised mitochondrial piRNA biogenesis results in Piwi proteins lacking bound piRNAs, which are consequently destabilized and degraded, ultimately leading to the transcriptional derepression of transposons (Wang and Elgin 2011; Sienski et al. 2012; Le Thomas et al. 2013; Rozhkov et al. 2013). In contrast, Aub/Ago3-mediated slicing of precursors and the ping-pong cycle are unaffected by loss of these factors.

Besides mitochondrially localized proteins, a number of cytosolic factors contribute to the process of piRNA biogenesis. Among these is Armitage (Armi), an RNA helicase of the Upf1 family, which localizes to nuage and mitochondria in germ cells and predominantly to $\mathrm{Yb}$ bodies in follicle cells (Malone et al. 2009; Olivieri et al. 2010; Saito et al. 2010). Armi shows ATP-dependent 5'-3' helicase activity (Pandey et al. 2017), and Zuc-mediated piRNA biogenesis-but not the ping-pong cycle-collapses upon its loss. Tethering of Armi to a reporter transcript results in conversion of the RNA into 25-nt piRNAs (Pandey et al. 2017; Rogers et al. 2017). The mouse homolog of Armi, MOV10L1, also binds to piRNA precursors and initiates the production of piRNAs (Vourekas et al. 2015). As a whole, these data place Armi at a critical juncture in piRNA biogenesis, where its binding to precursor transcripts is both necessary and sufficient to specify downstream piRNA production by Zuc and its mitochondrial cofactors.

Our current model of piRNA biogenesis identifies two subcellular compartments as being critical for piRNA production: nuage/Yb bodies, where precursor transcripts are recognized and processed into $5^{\prime}$-P intermediates, and mitochondria, where such intermediates are processively cleaved into mature piRNAs. While these two structures are often in physical proximity, it is unclear how they specifically interact to promote piRNA biogenesis. Here we identify a novel piRNA biogenesis factor, CG10880/Daedalus (Daed), which is anchored on the mitochondrial outer membrane. We show that Daed, together with Gasz, provides a mitochondrial binding platform for Armi, which is in turn essential for Zuc-mediated production of piRNAs. Our data suggest that Armi moves from nuage/Yb bodies, where it associates with piRNA precursors and Piwi, to mitochondria, where it remains in close association with Zuc during the processive cycle of piRNA production. We propose that loss of Gasz or Daed leads to impaired production of piRNAs due to the inability of the Armi-Piwi complex to be stably recruited to the mitochondrial surface, where it delivers precursor RNAs to Zuc.

\section{Results}

\section{CG10880/Daed is a mitochondrially localized protein} required for piRNA biogenesis

Comprehensive genetic screens in Drosophila have provided a molecular parts list for the piRNA pathway (Czech et al. 2013; Handler et al. 2013; Muerdter et al. 2013), yet how a number of these factors act to promote piRNA production or transposon silencing remains to be understood. Among such factors was CG10880, an uncharacterized Drosophila protein required for transposon silencing in the germline compartment of the ovary (Czech et al. 2013).

The gene encoding CG10880 is located on the left arm of chromosome 2 and shows its highest expression in ovarian tissues (Supplemental Fig. S1A). CG10880 contains a SAM domain (often involved in protein-protein or protein-RNA interaction), a coiled-coil domain (CC; typically involved in protein oligomerization and linked to diverse cellular functions), and a predicted transmembrane domain (TMM) at its C terminus (Fig. 1A). Depletion of CG10880 from the fly germline resulted in transposon derepression at levels comparable with those observed for knockdowns of zuc and gasz (Supplemental Fig. S1B) and in a strong delocalization of Piwi from nuclei, a hallmark of impaired piRNA biogenesis (Supplemental Fig. S1C). Interestingly, the CG10880 domain structure resembles that of Gasz (Supplemental Fig. S1D), a mitochondrial protein involved in piRNA biogenesis that also carries a SAM domain and a TMM at its $\mathrm{C}$ terminus.

To determine the localization of CG10880 in the fly ovary, we generated a line ubiquitously expressing an $\mathrm{N}$-terminally GFP-tagged fusion protein, GFP-CG10880, thus preserving its putative transmembrane domain. GFP-CG10880 localization overlapped with the mitochondrial marker Atp5a and was adjacent to but separate from nuage, as marked by Ago3 (Fig. 1B). Zuc-GFP (ubiquitously expressed) and GFP-Gasz (expressed from its endogenous promoter) (described in Handler et al. 2013) showed an indistinguishable localization pattern (Supplemental Fig. S1E). These results suggested that CG10880 could function as a mitochondrial piRNA biogenesis factor and prompted us to generate CG10880-null mutants. We derived two alleles: one harboring a deletion causing 
A

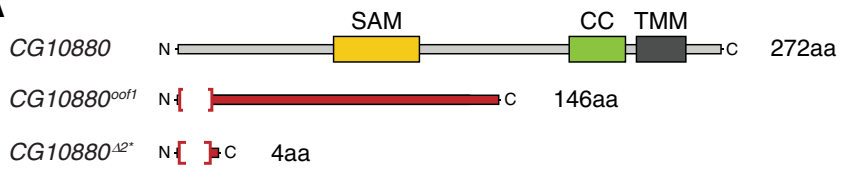

B

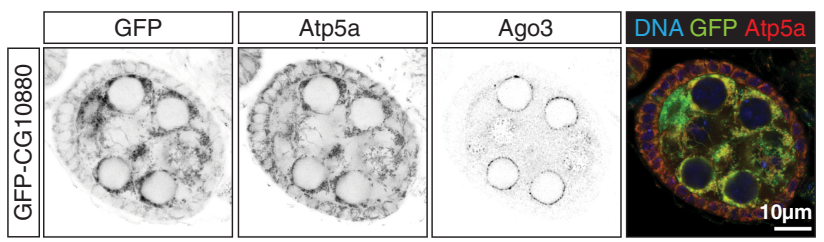

D

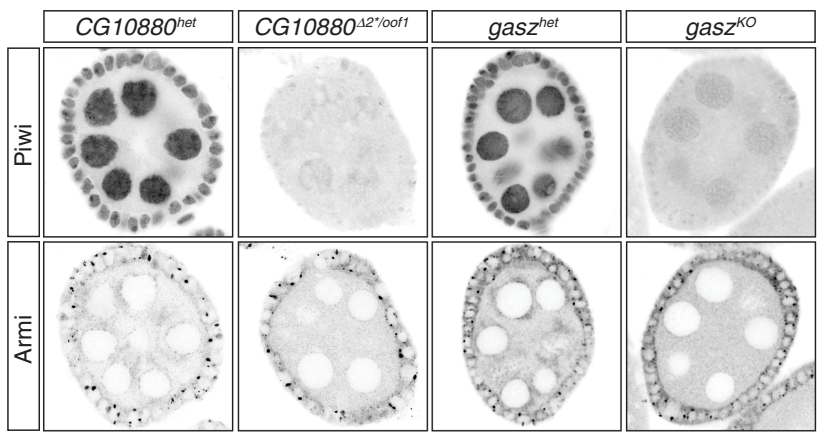

$\mathbf{F}$

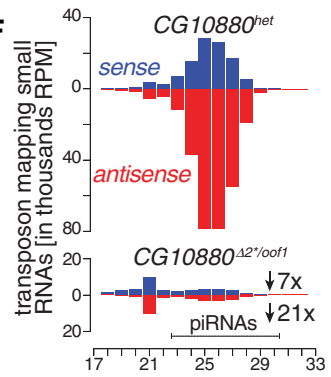

G

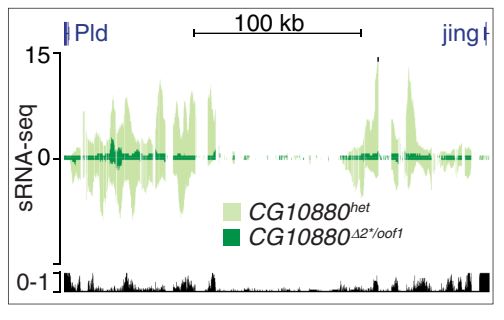

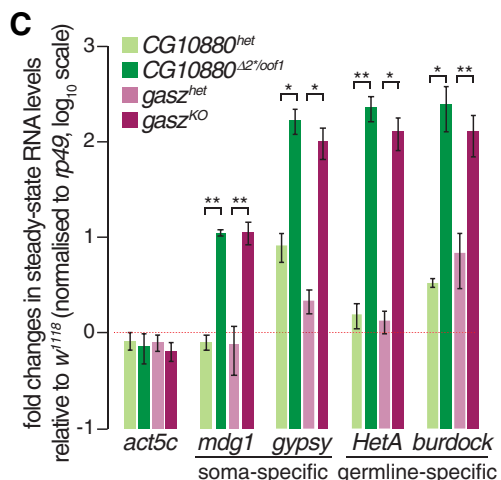

E

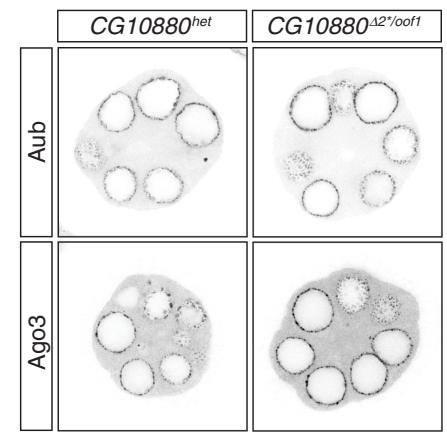

H

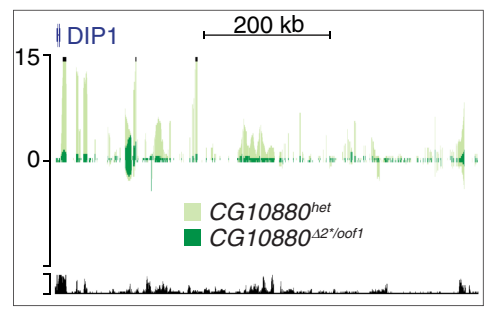

Figure 1. Daedalus is a mitochondrially localized protein involved in piRNA biogenesis. $(A)$ Schematic representation of the CG10880/ Daed domain structure and the two null alleles. Highlighted in red is the portion of coding sequence that is out of frame in the mutants. $(B)$ Confocal images of GFP-CG10880 in ovaries (see also Supplemental Fig. S1E). Scale bar, $10 \mu \mathrm{m}$. (C) Fold changes in steady-state RNA levels of the indicated soma- and germline-specific transposons from ovaries. Values are relative to $w^{1118}$ flies and normalized to $r p 49$. $\left.\left({ }^{*}\right) P<0.05 ;{ }^{* *}\right) P<0.001$ (unpaired $t$-test). Error bars indicate standard deviation. $n=4 .(D, E)$ Confocal images of Piwi, Armi, Aub, and Ago3 in ovaries (see also Supplemental Fig. S2C-E). (F) Size distribution of transposon-mapping small RNAs from ovaries. Sense reads are shown in blue, and antisense reads are in red. $(G, H)$ Coverage plots of small RNA reads uniquely mapped to the dual-strand cluster $42 A B(G)$ and the unistrand cluster flamenco (flam) $(H)$. Shown are normalized reads per million (RPM). The mappability for an average 25 -bp read length is shown at the bottom.

a frameshift (CG10880 $0^{\circ}$ ) and a second deletion that results in a premature stop codon $\left(C G 10880^{\Delta 2^{*}}\right.$ ) (Fig. 1A). Homozygous mutant females laid fewer eggs, which showed abnormal morphology without dorsal appendages and did not hatch, similarly to gasz homozygous mutants (Supplemental Fig. S2A) generated via RFP knock-in in the gasz genomic locus (gasz ${ }^{K O}$ ) (Supplemental Fig. S2B). CG10880 transheterozygous and gasz homozygous mutants displayed impaired repression of both somatic and germline transposons (Fig. 1C). Piwi nuclear localization was severely compromised in somatic and germline cells of mutant flies (Fig. 1D; Supplemental Fig. S2C), whereas the nuage localization of Aub, Ago3, and Vasa was unperturbed (Fig. 1E; Supplemental Fig. S2D). This implied that CG10880 is likely involved in the generation of Piwi-loaded piRNAs but not the ping-pong cycle. Interestingly, CG10880 mutants also displayed an altered distribution of the RNA helicase Armi, which is normally localized to nuage and mitochondria (Fig. 1D; Supplemental Fig. S2C). Notably, the same phenotype is observed in gasz mutant (Fig. 1D; Supplemental Fig. S2C) and knockdown (Handler et al. 2013) flies. Finally, CG10880-null mutants had highly altered mitochondrial morphology (Supplemental Fig. S2E), again closely resembling what is observed upon gasz loss (Supplemental Fig. S2E; Handler et al. 2013). These results suggest that CG10880 is a bona fide piRNA biogenesis factor involved in Zuc-mediated processing of phased piRNAs on mitochondria, and, 
since it is essential for the correct assembly of the mitochondrial "labyrinth" in germ cells, we named it Daedalus (Daed).

In germ cells, piRNA biogenesis is initiated in nuage, where the ping-pong cycle, driven by Aub and Ago3, generates long $5^{\prime}-\mathrm{P}$ piRNA precursors. These are further processed by Zuc on the outer mitochondrial surface, resulting in the sequential generation of phased piRNAs. With the goal of understanding which biogenesis step is affected by the loss of Daed, we sequenced small RNAs from mutant ovaries. Repeat-derived small RNAs were dramatically reduced in daed transheterozygous mutants, as compared with their heterozygous siblings (6.9-fold and 20.8-fold for sense and antisense, respectively) (Fig. 1F), whereas repeat-derived siRNAs remained unchanged (21-nt peak in Fig. 1F). piRNAs originating from germline dual-strand clusters, somatic unistrand clusters, and protein-coding genes were all strongly reduced (Fig. 1G, $\mathrm{H}$; Supplemental Fig. S3A), indicating an essential role of Daed in Zuc-dependent processing of piRNA precursors in both major ovarian cell types. Consistent with this hypothesis, the ping-pong signature of repeat-derived piRNAs was unaffected (Supplemental Fig. S3B). As expected, small RNAs in gasz ${ }^{K O}$ recapitulated the phenotype of daed mutants (Supplemental Fig. S3B-D).

\section{Daed is essential for recruitment of Armi to mitochondria}

Ovarian somatic cells (OSCs) cultured in vitro express a functional Piwi-piRNA pathway (without the ping-pong cycle) and therefore provide a convenient context in which to investigate piRNA biogenesis (Niki et al. 2006; Saito et al. 2009). Immunostaining of OSCs transfected with 3xFlag-tagged Daed showed localization to mitochondria, but removal of the putative TMM domain caused its redistribution throughout the cell (Daed ${ }^{\triangle T M M}$ ) (Fig. 2A). Additionally, Daed colocalizes with both Zuc and Gasz (Fig. 2A).

Aiming to understand the role of Daed in piRNA biogenesis, we set out to identify its interacting partners via in vivo proximity labeling with biotin (Roux et al. 2012; Kim et al. 2016). The strength and stability of the biotin-streptavidin interaction allows very stringent pull-down conditions that successfully isolate membrane proteins, and, as a further advantage, proximity labeling allows the capture of even weak or transient interactions that would escape detection with standard immunoprecipitation-mass spectrometry (IP-MS) techniques. We found that the Bacillus subtilis biotin ligase (BASU) (Ramanathan et al. 2018) showed robust activity in fly cells at $26^{\circ} \mathrm{C}$ and therefore expressed an HA-BASU-Daed fusion in OSCs. Western blot on lysates of cells expressing the fusion showed the appearance of biotinylated proteins in addition to those endogenously present (Fig. 2B, asterisks) when compared with cells expressing ZsGreen without biotin ligase. Biotinylated proteins were efficiently recovered using streptavidin beads (Supplemental Fig. S4A) and were subjected to quantitative MS (referred to here as proximity labeling MS [PL-MS]). BASU-Daed itself was highly enriched in the pull-down (consistent with the self-biotinylation of any BASU fusion protein) (Fig. 2B, arrowhead), along with other known piRNA pathway factors (Fig. 2C; Supplemental Table S1). Strikingly, Daed PL-MS enriched for mitochondrial (Papi, Mino, and Gasz) as well as cytosolic (SoYb, Piwi, and Armi) piRNA pathway proteins. Similarly, BASU-Gasz PL-MS also enriched for Armi and Piwi (Supplemental Fig. S4B; Supplemental Table S2). Together with the observation that Armi is mislocalized in gasz and daed mutants, these data raise the possibility that a Gasz/Daed transmembrane complex might anchor Armi onto mitochondria to achieve efficient piRNA production.

To test this hypothesis, we coexpressed Daed, Gasz, and ZsGreen in Schneider 2 (S2) cells and probed their interaction by anti-Flag coimmunoprecipitation (coIP). Both 3xFlag-Daed and 3xFlag-Gasz coimmunoprecipitated with HA-Daed and HA-Gasz but not with HAZsGreen, suggesting both homotypic and heterotypic interactions on the mitochondrial surface (Fig. 2D), although we cannot rule out the possibility that other proteins act as bridges in a larger complex. The mitochondrial marker Atp5a showed no enrichment in the immunoprecipitation, implying that the association of Gasz and Daed is not an artifact of intact mitochondria being isolated (Fig. 2D). To further investigate Daed and Gasz homotypic or heterotypic interaction, we expressed 3xFlag-tagged Daed, Gasz, or Zuc in S2 cells. The latter served as a positive control, since Zuc is known to exist in a dimeric conformation (Ipsaro et al. 2012; Nishimasu et al. 2012). We chemically cross-linked the cells to stabilize any putative complexes and performed anti-Flag pulldowns. Upon cross-linking, Zuc immunoprecipitation showed a second band at double the size of the fusion protein itself, thus likely corresponding to the dimer (Supplemental Fig. S4C, light-green arrowhead). Strikingly, a similar pattern was observed for Gasz and Daed (Supplemental Fig. S4C, purple and dark-green arrowheads) but not for ZsGreen.

To identify the regions that mediate these interactions, we performed 3xFlag-Gasz coIP with Daed deletion constructs lacking individual domains (Supplemental Fig. S4D). These experiments revealed that the Daed-Gasz interaction depends on the CC domain of Daed (Fig. 2E). Considered together, these data indicate that Gasz and Daed interact on the mitochondrial surface as direct binding partners. HA-tagged Armi also coimmunoprecipitated with both Gasz and Daed, thus indicating that its enrichment in Daed and Gasz PL-MS reflects interactions within the same complex rather than just physical proximity (Fig. 2F).

Knockdown of daed in OSCs leads to somatic transposon derepression (Supplemental Fig. S4E), which could be rescued by re-expression of siRNA-resistant Daed ${ }^{\text {WT }}$ and Daed ${ }^{\triangle T M M}$ but not those lacking the SAM or CC domains (Fig. 2G). Daed ${ }^{\triangle T M M}$ could still interact with mitochondrial Gasz and function normally, in contrast to Daed $^{\triangle S A M}$, which, albeit still associating with Gasz, appeared to be unable to exert its role. This potentially implicates the SAM domain in the interaction with either 


\section{A}
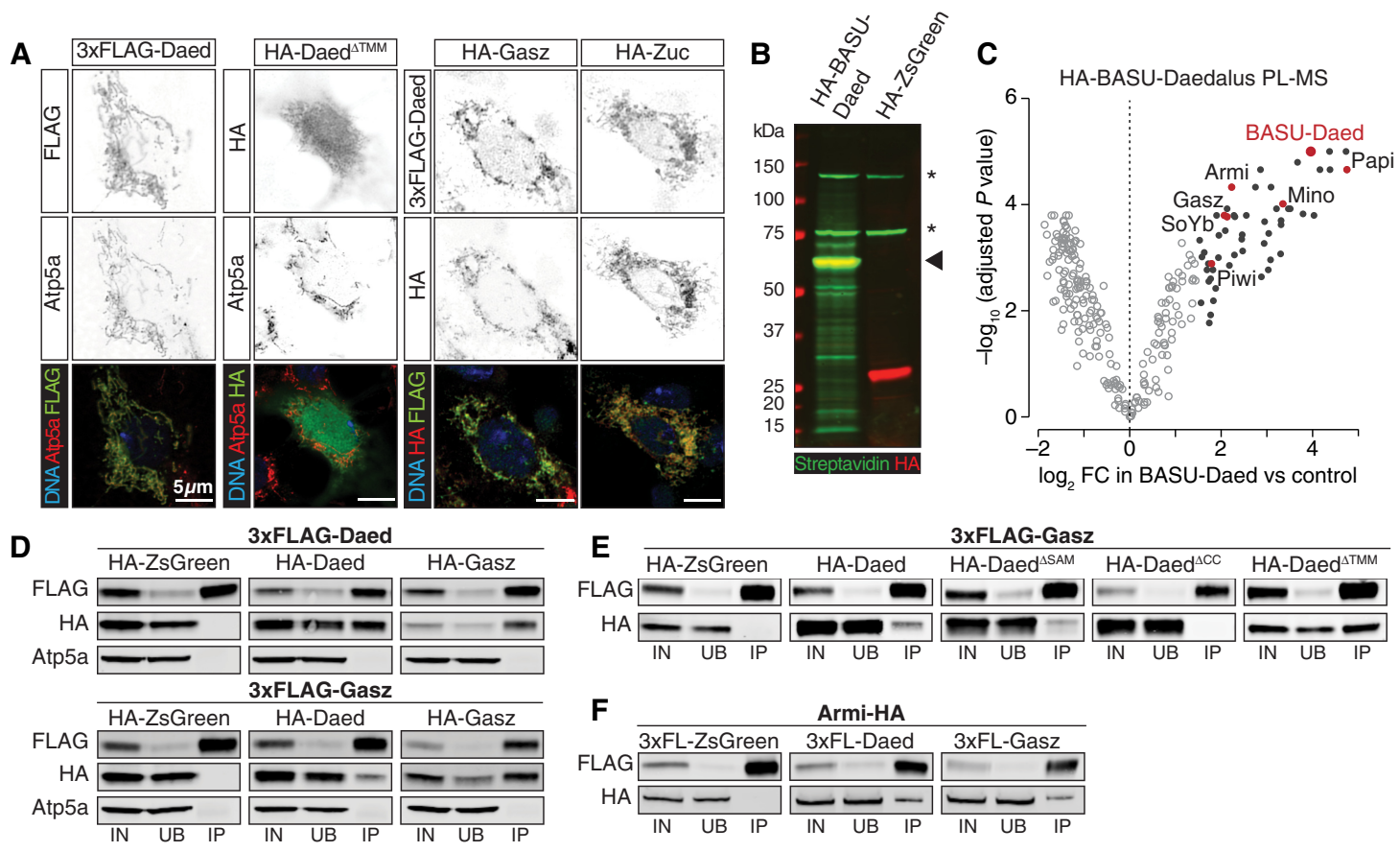

3xFLAG-Daed
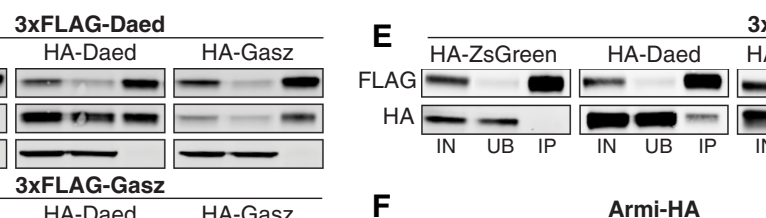

3xFLAG-Gasz

3XF-DaedISAM HA-DaedicC HA-Daed
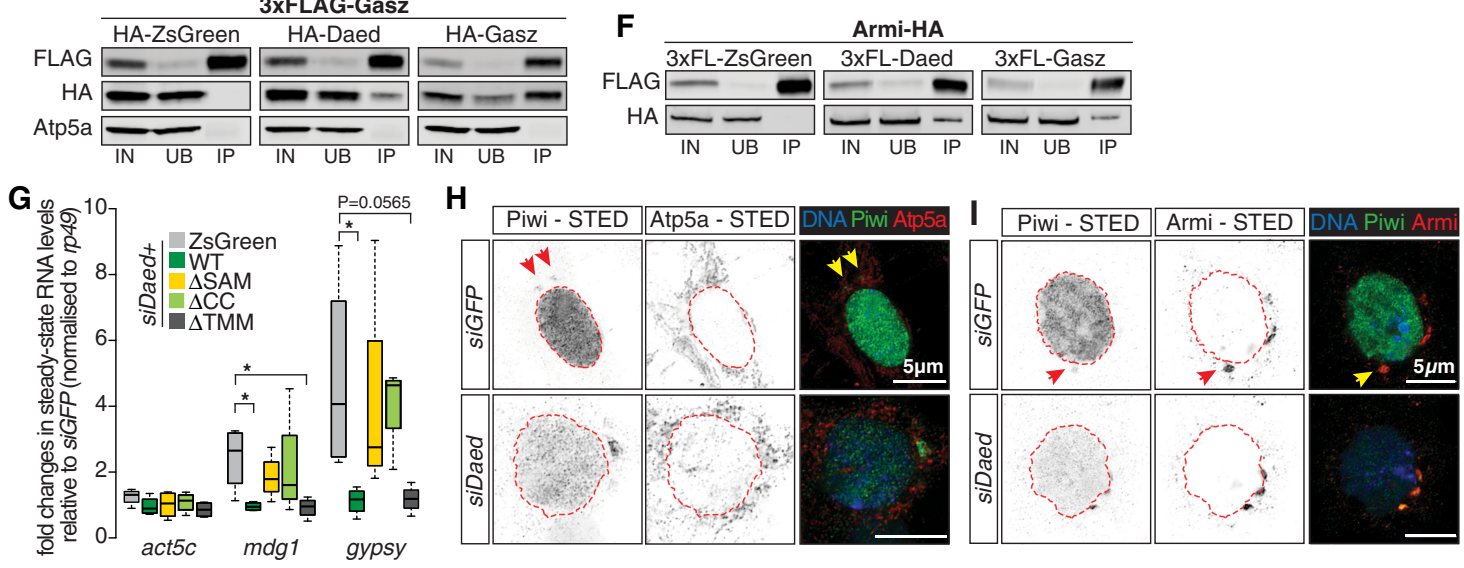

Figure 2. Daed interacts with Gasz, and these together promote Armi localization on mitochondria. $(A)$ Confocal images of fusion constructs and the mitochondrial marker Atp5a in OSCs. Scale bar, $5 \mu \mathrm{m}$. $(B)$ Western blot showing biotinylated proteins (in green; detected with streptavidin) upon expression of HA-BASU-Daed compared with the HA-ZsGreen control. Asterisks indicate endogenously biotinylated proteins, and the arrowhead indicates the size of HA-BASU-Daed fusion. Note that HA-BASU-Daed fusion biotinylates itself (green and red signal overlap). (C) Volcano plot showing enrichment and corresponding significance of biotinylated proteins identified via quantitative mass spectrometry from OSCs expressing BASU-Daed versus control. $n=2$. Black dots indicate proteins showing a log fold $_{2}$ change of $>1.5$ and adjusted $P$-value of $<0.05$ in BASU-Daed. Highlighted in red are piRNA pathway factors. A full list of enriched proteins is in Supplemental Table S1. $(D-F)$ Western blots of Flag tag coimmunoprecipitation from lysates of Schneider 2 (S2) cells transfected with the indicated constructs. (IN) Input; (UB) unbound; (IP) immunoprecipitate. (G) Fold changes in the steady-state RNA levels of somatic transposons in OSCs nucleofected with siRNAs and various rescue constructs. Values are relative to GFP control knockdown and normalized to $\left.r p 49 .{ }^{*}\right) P<0.05$ (unpaired $t$-test). $n=4$. $(H, I)$ Stimulated emission depletion (STED) microscopy of Piwi and Atp5a $(H)$ or Piwi and Armi $(I)$ in OSCs from the indicated knockdowns. Scale bar, $5 \mu \mathrm{m}$.

Armi or RNA. Piwi nuclear localization was markedly reduced in OSCs depleted of Daed (Supplemental Fig. S4F), and Piwi appeared to be retained with Armi in Yb bodies (arrow in Supplemental Fig. S4F), a phenotype that was also observed in follicle cells of daed and gasz mutant flies (arrows in Supplemental Fig. S4G). These results suggest that, in the absence of Daed and Gasz, Piwi and Armi fail to leave $\mathrm{Yb}$ bodies to translocate to mitochondria. We therefore exploited high-resolution imaging using stimulated emission depletion (STED) microscopy to better understand the consequences of Daed depletion in OSCs. In wild-type cells, Piwi was detected in close asso- ciation with mitochondria (Fig. $2 \mathrm{H}$, arrows; Supplemental Fig. S4H), whereas, upon daed knockdown, the majority of the remaining Piwi became confined to discrete Yb bodies surrounded by morphologically altered mitochondria (Fig. 2H). Costaining of Piwi and Armi showed that, when outside the nucleus, Piwi was generally observed in proximity with Armi (Fig. 2I; Supplemental Fig. S4I). Taken together, these data suggest a model in which Piwi moves onto the mitochondrial surface, where Armi is positioned in a manner dependent on Daed and Gasz, but is unable to reach these processing sites upon depletion of daed or gasz. 
Armi shuttles from $\mathrm{Yb}$ bodies to mitochondria, where it associates with dimeric Zuc

To gain a better understanding of protein-protein interactions occurring on the mitochondrial surface during piRNA biogenesis, we also carried out PL-MS for Armi and Zuc (Fig. 3A,B; Supplemental Fig. S5A,B). ArmiBASU PL-MS enriched for $\mathrm{Yb}$ and Piwi (Fig. 3A), both reported previously as Armi interactors (Olivieri et al. 2010; Saito et al. 2010), thus validating the sensitivity of our method. In addition, we noted enrichment of other cytosolic (Shu, SoYb, and Spn-E) and mitochondrial (Papi, Gasz, Daed, and Mino) piRNA biogenesis factors (Fig. 3A; Supplemental Table S3). Interestingly, PL-MS for Zuc-BASU identified several mitochondrial components of the piRNA biogenesis machinery (Papi, Mino, Daed, and Gasz) but also demonstrated strong enrichment of Armi and, to a lesser extent, SoYb (Fig. 3B; Supplemental Table S4), implying tight association of these factors during piRNA production. Structural studies strongly indicate that Zuc cleaves RNA as a dimer (Ipsaro et al. 2012; Nishimasu et al. 2012); thus, we decided to exploit this feature to further refine our proteomics analysis and attempt to pinpoint which piRNA pathway factor is more closely associated with the "cleavage-competent" Zuc dimer. We applied the Split-BioID method, in which the Escherichia coli biotin ligase BirA* is divided into two fragments ( $\mathrm{N}$-terminal and $\mathrm{C}$-terminal $\left.\mathrm{BirA}^{*}\right)$, each inactive on its own (Supplemental Fig. S5C, lanes 2,3; Schopp et al. 2017). N-BirA* and C-BirA* reconstitute the active enzyme only if fused to two proteins that interact in vivo, as in the case of the Zuc dimer, and upon biotin supplementation (Supplemental Fig. S5C, last lane; Supplemental Fig. S5D). The reconstituted BirA* exhibited much lower activity than BASU, thus generating a smaller number of biotinylated proteins (Supplemental Fig. S5D). Strik- ingly, PL-MS using Split-BioID revealed enrichment of a limited set of proteins yet still readily identified Armi (Fig. 3C; Supplemental Table S4). This could imply a closer association of Armi with the Zuc dimer than, for instance, SoYb, which was identified only by Zuc-BASU PL-MS. Knockdown of zuc and armi in OSCs caused more similar changes in the levels of genome-mapped small RNAs $\left(r^{2}=\right.$ 0.782) (Supplemental Fig. S5E) than zuc versus yb depletion $\left(r^{2}=0.406\right)$ (Supplemental Fig. S5F), further supporting a role for Armi as a proximate Zuc cofactor.

Based on this, we envisioned a model in which a PiwiArmi complex is licensed at the sites of pre-piRNA specification (nuage in germ cells and $\mathrm{Yb}$ body in follicle cells/ OSCs) and then translocates to mitochondria. There, Armi is held in place by Gasz/Daed and engages in piRNA production in close association with Zuc. Consistent with this model, in both fly germline and OSCs, loss of zuc causes a dramatic accumulation of Piwi and Armi on mitochondria, whereas loss of gasz and daed leads to their dispersal in the cytosol or concentration in $\mathrm{Yb}$ bodies (Fig. 3D,E; Supplemental Fig. S5G). We therefore suggest that Armi shuttles from nuage/Yb bodies to mitochondria and is involved in the presentation of piRNA precursors to Zuc, enabling their downstream processing into phased piRNAs.

\section{Armi depends on Piwi for binding to piRNA precursors}

Armi belongs to the family of Upf1-like RNA helicases, and its mouse homolog, MOV10L1, has been shown to bind to pre-piRNAs (Vourekas et al. 2015). Therefore, we sought to determine whether Drosophila Armi associates with the piRNA precursors that will be presented to Zuc for phased cleavage. CLIP-seq (cross-linking immunoprecipitation [CLIP] combined with deep sequencing) for an
A
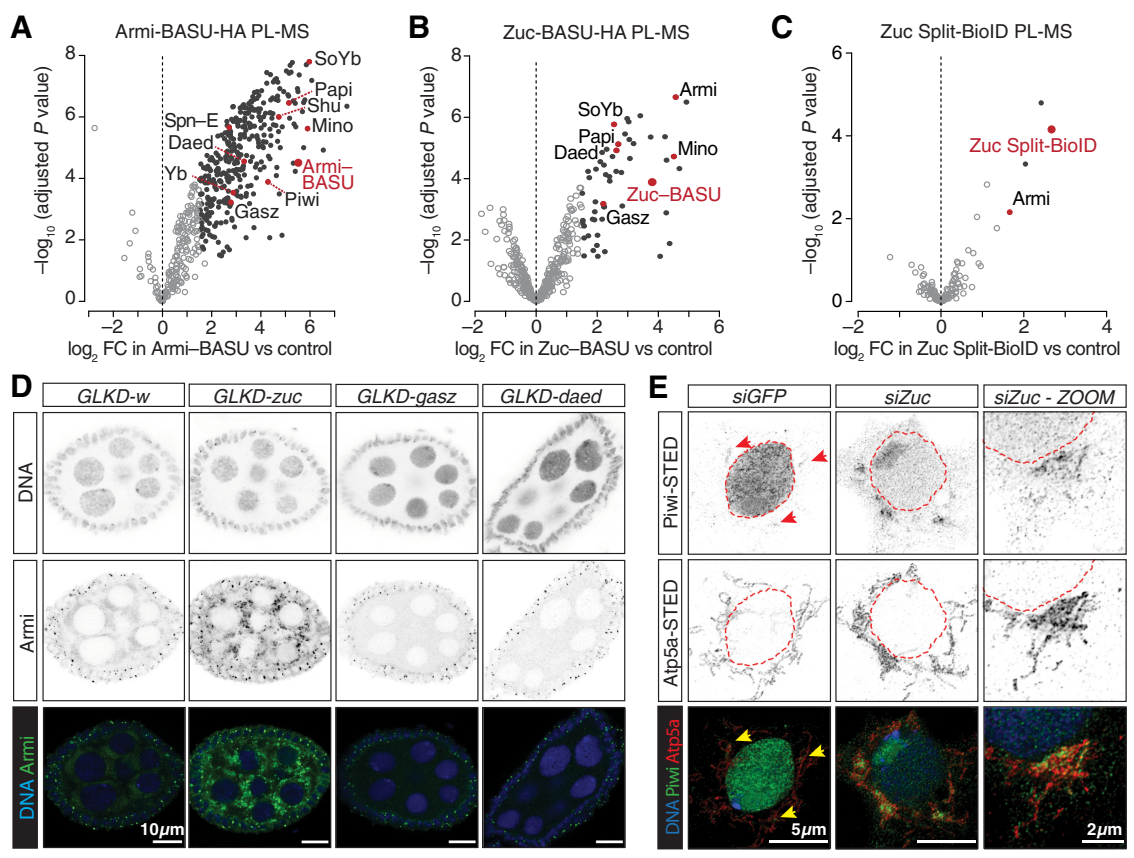

Figure 3. Armi localizes to mitochondria in proximity to the piRNA processing machinery. $(A-C)$ Volcano plots showing enrichment and corresponding significance of biotinylated proteins identified via PL-MS from OSCs expressing the indicated constructs against control. $n=3$. Black dots indicate proteins showing a $\log _{2}$ fold change of $>1.5$ and adjusted $P$-value of $<0.05$. piRNA pathway factors are highlighted in red. A full list of enriched proteins is in Supplemental Tables S3-S5. (D) Confocal images of Armi in ovaries from the indicated germline knockdown. Scale bar, $10 \mu \mathrm{m}$. (E) STED microscopy of Piwi and Atp5a in OSCs. Scale bar, $5 \mu \mathrm{m}$. 
Armi-HALO fusion expressed in OSCs (Supplemental Fig. S6A) showed substantial enrichment of somatic piRNA source transcripts: the unistrand piRNA clusters flamenco (flam) and 20A (Fig. 4A, red) and a number of protein-coding genes known to give rise to genic piRNAs (Fig. 4A, blue). We found Armi distributed along the entire length of piRNA precursor transcripts even when they span several hundred kilobases, such as in the case of flam (Fig. 4B). On genic transcripts, Armi cross-linked preferentially to their $3^{\prime}$ untranslated regions (UTRs), as exemplified by $t j$ (Fig. 4C). In all cases, sequences enriched in Armi CLIP-seq corresponded with those appearing as piRNAs that were lost upon armi knockdown (Fig. $4 \mathrm{~B}, \mathrm{C}$, bottom panels). When analyzing the presence of transposon content in Armi CLIP-seq, we found an enrichment for antisense sequences, especially those that are present in flam (Fig. 4D, red, with dot size proportional to their abundance within flam). We did not detect substantial enrichment of transposon sense sequences (Fig. 4E). No $1 \mathrm{U}$ bias was detected in Armi CLIP-seq, but this is likely a result of our library preparation procedure and is also consistent with what is reported for mouse MOV10L1 (Vourekas et al. 2015). Thus, our data support a model in which Armi specifically binds to a subset of cellular transcripts and assists their processing into piRNAs. However, a key issue remains as to how such precursors are selectively discriminated by Armi from other cellular RNAs.
The prevailing model suggests that Zuc simultaneously forms piRNA $3^{\prime}$ and $5^{\prime}$ ends by cleaving downstream from Piwi, while Piwi is positioned on the $5^{\prime}$ end of a longer piRNA precursor (Gainetdinov et al. 2018). Precisely how Armi fits into this process remains unclear, yet it does definitively also engage piRNA precursors. We therefore examined the interactions between Armi and piRNA precursors in the context of either piwi, zuc, or gasz knockdown (Fig. 5A-C; Supplemental Fig. S6C-E). Upon depletion of Piwi, we detected a substantial decrease, but not complete loss, of the binding of Armi to ti, flam, and 20A, the main sources of piRNAs in OSCs (Fig. 5A). We suggest that the binding is not entirely lost due to the persistence of some Piwi protein in knockdown samples (Supplemental Fig. S6B). In contrast, upon knockdown of zuc, Armi CLIP-seq indicated an increase in precursor transcript binding (Fig. 5B). Interestingly, the Armi footprint on the $t j$ mRNA was not evenly affected by zuc depletion, but, importantly, increases were restricted to the $3^{\prime}$ UTR, which is precisely the part of the ti mRNA that is converted into piRNAs. Finally, gasz knockdown did not globally affect Armi CLIP-seq signal (Fig. 5C), which is in accordance with our model postulating that Armi binds to precursor RNAs before translocating on mitochondria. Quantification of CLIP-seq signals for selected regions of flam and $20 \mathrm{~A}$ that show good mappability (Fig. 5A-C, orange boxes) and those for the tij CDS, $5^{\prime}$ UTR, and 3' UTR confirmed increased association of

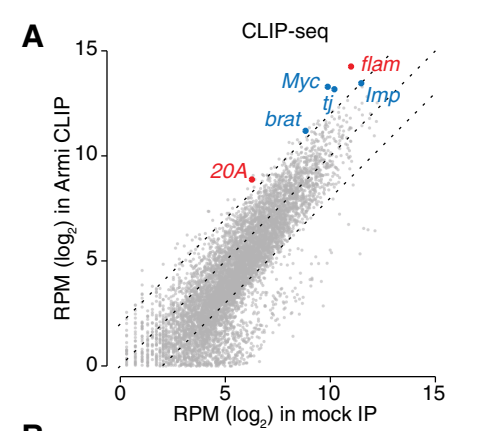

B
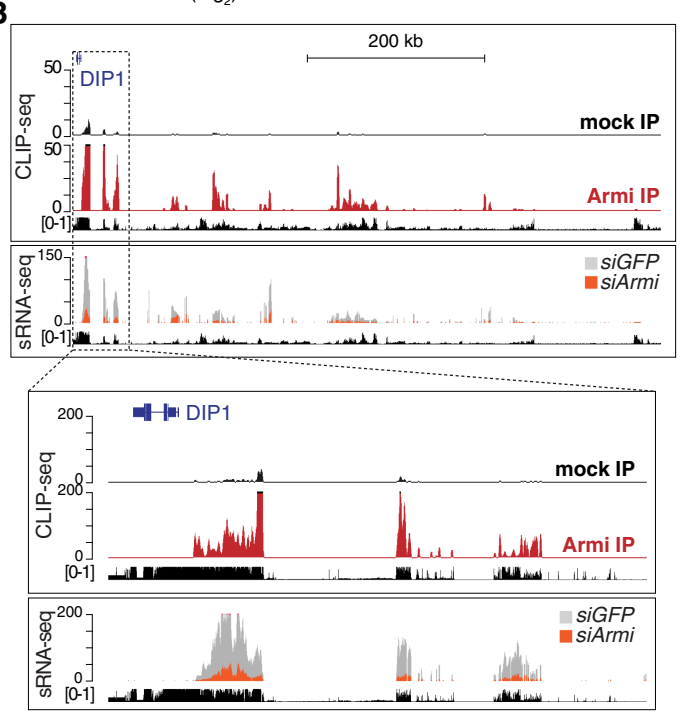

C

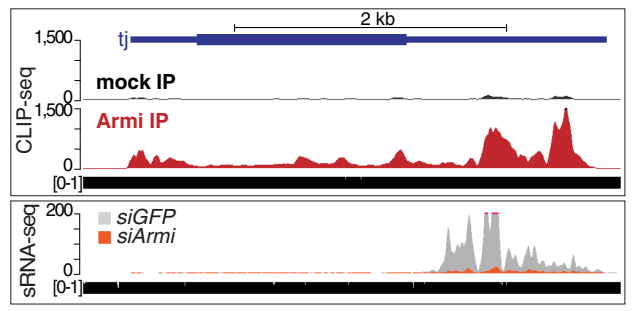

D Antisense transposon sequences

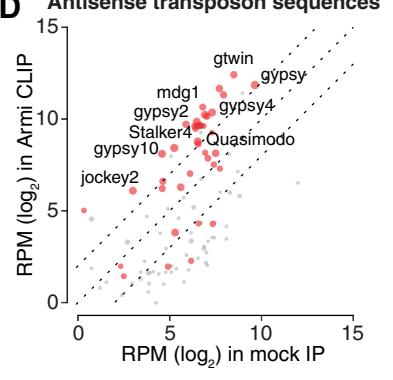

E

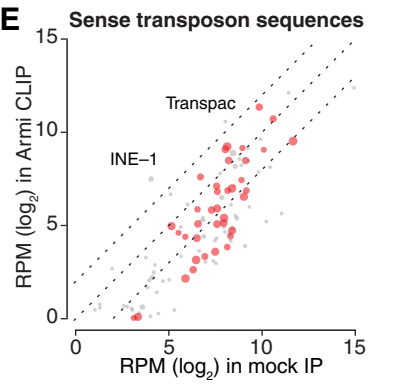

Figure 4. Armi binds to piRNA precursors. (A) Scatter plot showing expression levels (RPM) of genes in Armi CLIP-seq $(n=4)$ against a mock immunoprecipitation $(n=$ 3). piRNA clusters expressed in OSCs are highlighted in red, and selected protein-coding genes producing piRNAs are in blue. (B) Genome browser shot displaying Armi CLIP-seq and small RNA sequencing (sRNA-seq) reads uniquely mapping to the piRNA cluster flam (top panel) and a zoomed-in view of the first $\sim 50 \mathrm{~kb}$ (bottom panel). Shown are normalized RPM. The mappability tracks for 50- and 25-bp read lengths, respectively, are shown below. (C) Same as in $B$ but showing the proteincoding gene $t j .(D, E)$ Scatter plots showing expression levels (RPM) of antisense and sense transposon sequences in Armi CLIPseq against a mock immunoprecipitation. Transposon sequences present in flam are highlighted in red, with dot size proportional to their abundance within flam according to dm6 Repeat Masker annotations. 

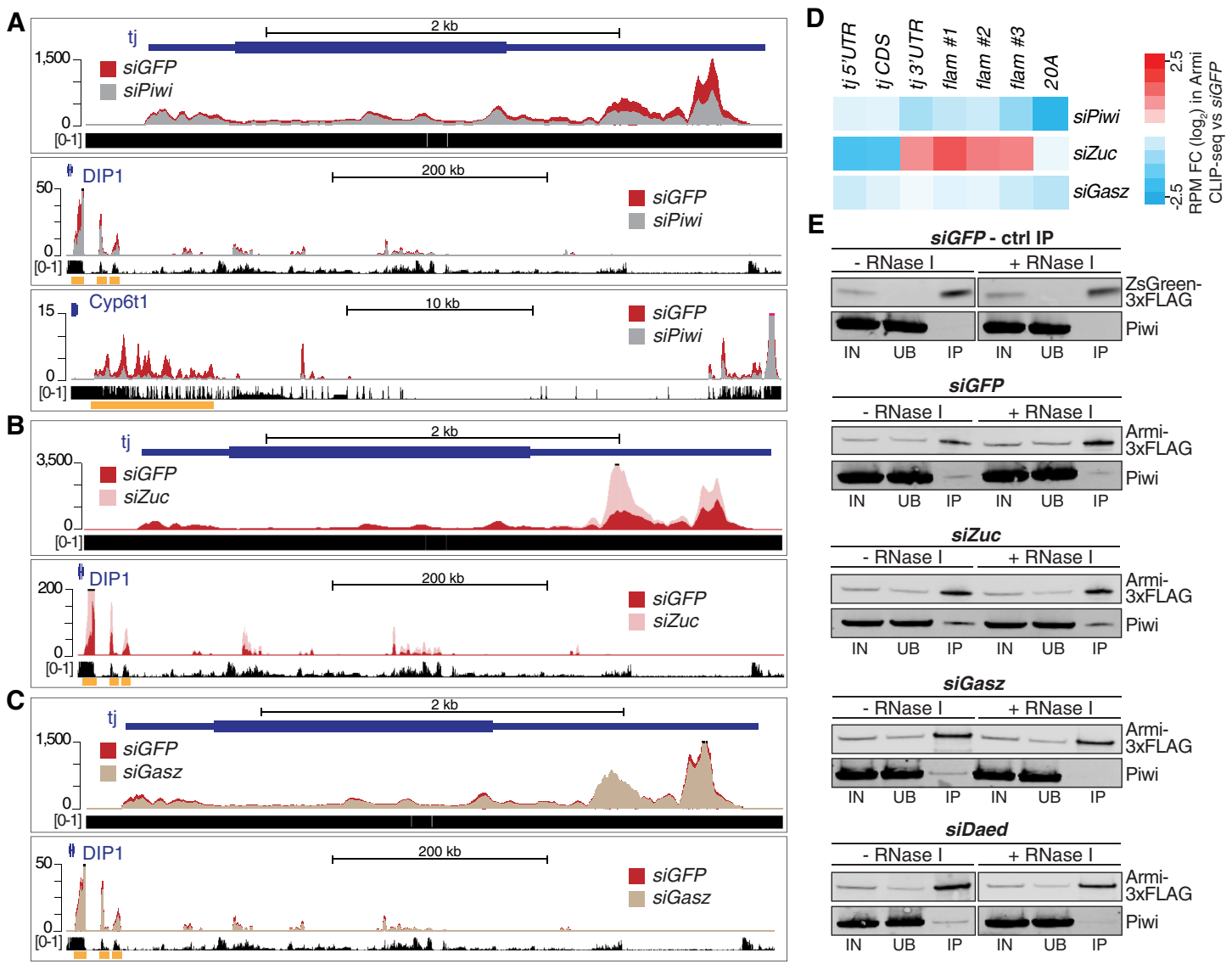

Figure 5. Armi binding to piRNA precursors is impaired upon piwi knockdown. $(A-C)$ Genome browser shot displaying Armi CLIP-seq profiles from OSCs upon the indicated knockdown. Normalized RPM are shown. $n=3$ for siZuc and relative siGFP control; $n=4$ for siPiwi and relative siGFP control; $n=3$ for siGasz and relative siGFP control. The mappability tracks for 50-bp read length are shown below each profile. (D) RPM $\log _{2}$ fold change in Armi CLIP-seq upon the indicated knockdown against their relative siGFP for selected regions of $t j$, flam, and $20 A$ (orange boxes in $A-C$ ). (E) Western blots of ZsGreen-3xFlag or Armi-3xFlag coIP from lysates of OSCs upon the indicated knockdown. (IN) Input; (UB) unbound; (IP) immunoprecipitate.

Armi with precursors in zuc knockdowns, while piwi depletion resulted in reduced Armi binding (Fig. 5D).

To investigate whether the dependency of Armi precursor binding on Piwi might stem from a physical association between these proteins, we immunoprecipitated Armi-3xFlag and probed for the presence of endogenous Piwi. Immunoprecipitation of Armi-3xFlag from wildtype cells resulted in the recovery of only a small amount of Piwi (Fig. 5E; quantification in Supplemental Fig. S6F). However, upon zuc knockdown, despite an overall reduction in Piwi levels, the amount of Piwi complexed with Armi rose, and this association was insensitive to RNase (Fig. 5E; Supplemental Fig. S6F). Interestingly, gasz and daed knockdown did not generally impact the association of Armi and Piwi but instead made that interaction sensitive to RNase treatment (Fig. 5E; Supplemental Fig. S6F).

\section{Discussion}

The biogenesis of piRNAs requires a highly specialized machinery that must recognize the correct precursors in
$\mathrm{Yb}$ bodies or nuage, transport them to the surface of mitochondria, and parse them into trails of $\sim 25$-nt piRNAs. How each step is achieved and how information flows between the discrete subcellular compartments in which piRNA biogenesis is initiated and completed are yet to be fully understood.

Here, we expand the repertoire of mitochondrial piRNA biogenesis factors by identifying and characterizing CG10880/Daed. Daed is expressed predominantly in the female germline and appears to be unique to Drosophilids (Supplemental Fig. S7). Its domain structure is similar to that of Gasz, a previously described mitochondrial piRNA biogenesis factor that is conserved across species. Although it is not clear why Drosophilids possess two proteins with related structure and function, our data indicate that Daed and Gasz assemble as homopolymeric and heteropolymeric complexes (Fig. 6, middle) and act together to promote localization of Armi on mitochondria in a nonredundant manner. It is likely that recruitment of Armi to the mitochondrial surface is key for delivery of piRNA precursor transcripts to the nuclease $\mathrm{Zuc}$, and the importance of Daed/Gasz in this process is confirmed 


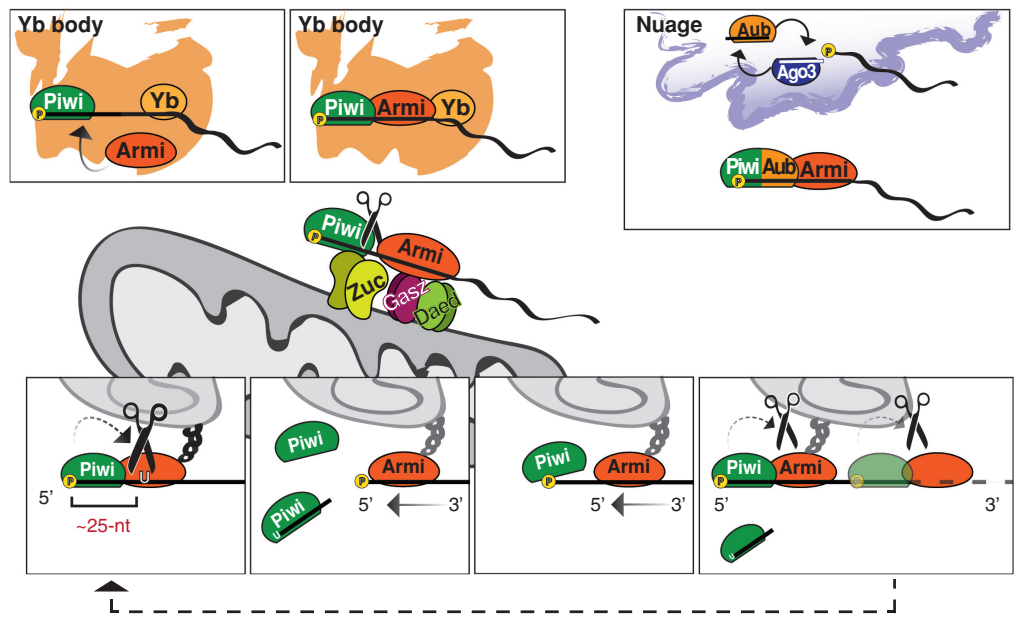

Figure 6. A model for piRNA biogenesis. (Top) In $\mathrm{Yb}$ bodies, Piwi binds to the 5 ' phosphate of a piRNA precursor, and this in turn recruits Armi. (Middle) Piwi, Armi, and the substrate RNA translocate to mitochondria, where a Daed/Gasz complex stabilizes Armi, while Zuc dimers cleave the transcript. Phased piRNA production then requires cycles of Piwi binding positioning Zuc to cleave at the first available uridine. (Bottom) While held in place by Daed and Gasz, Armi translocates along the transcript to provide the next segment of the RNA for piRNA biogenesis, and, again, Piwi binding to the newly generated $5^{\prime}-\mathrm{P}$ restarts the process. by not only our own data but also the conservation of a role for Gasz in transposon control across animals (Zhang et al. 2016). Intriguingly, Gasz and Daed loss similarly perturbs mitochondrial morphology, and Zuc depletion has been shown to result in mitochondrial clustering/Olivieri et al. 2012). It is presently unclear how changes in piRNA biogenesis produce such dramatic morphological impacts, but this observation further underscores the intimate relationship between mitochondria and the transposon control machinery in the ovary.

Our data indicate that the sites of piRNA precursor specification and processing communicate via translocation of precursors marked by binding of Piwi and Armi from Yb bodies/nuage to dimeric Zuc on the mitochondrial surface. Although our proteomics experiments identified several cytosolic piRNA biogenesis factors as being adjacent to mitochondria, among those, Armi appeared to be the one in closest proximity to Zuc. This could imply that Armi's role is to ensure the processivity of Zuc cleavage by presentation of RNA substrates via its ATP-dependent RNA helicase activity. Indeed, upon zuc knockdown, Armi and Piwi are trapped on mitochondria in an RNAbound state, presumably because the subsequent step in piRNA generation is blocked. It is interesting to note that Armi binding to RNA depended on Piwi (Fig. 5A). This provides a potential link between the recognition of a piRNA precursor in nuage and $\mathrm{Yb}$ bodies via Piwi/Aub binding to its $5^{\prime}$-P end and the subsequent association with Armi and flow into downstream processing. Since all factors involved are expressed in both compartments of the fly ovary, this model might apply equally to nurse and follicle cells.

Considered as a whole, our data support a model (Fig. 6) in which 5'-P piRNA precursors in nuage or $\mathrm{Yb}$ bodies are first bound by Piwi or Aub. Substrates defined in this way can then recruit Armi. This complex must then translocate to mitochondria, where Gasz and Daed anchor Armi adjacent to dimeric and active Zuc, potentially via its associated precursor RNA. Once held in place on the mitochondrial surface, the Armi-Piwi interaction is stabilized independently of RNA, and the cycle of piRNA production can initiate. At this stage, mitochondrially anchored Armi likely unwinds or translocates along the precursor RNAs to allow Piwi to sequentially bind to each free $5^{\prime}$-P end generated after each Zuc cleavage event. The Piwi footprint in turn determines the next Zuc cleavage site upstream of the first accessible uridine. However, what mechanism dictates this particular Zuc cleavage preference remains an outstanding question.

\begin{abstract}
Materials and methods
Cell culture

OSCs were a gift from Mikiko Siomi and were cultured as described (Niki et al. 2006; Saito et al. 2009; Saito 2014). Knockdowns (all siRNA sequences are in Supplemental Table S6) and transfections in OSCs were carried out as described previously (Saito 2014). All constructs used in cells were expressed from the Drosophila act5c promoter. Drosophila S2 cells were purchased from Thermo Fisher Scientific and grown at $26^{\circ} \mathrm{C}$ in Schneider medium supplemented with $10 \%$ FBS. S2 cells were transfected using Effectene (Qiagen) according to the manufacturer's instructions.
\end{abstract}

\section{$B A S U$ proximity labeling and $M S$}

OSCs $\left(4 \times 10^{6}\right)$ were transfected with $20 \mu$ of plasmid expressing an HA-BASU fusion or HA-ZsGreen. After $48 \mathrm{~h}$, the medium was supplemented with $200 \mu \mathrm{M}$ biotin for $1 \mathrm{~h}$. Cell pellets were lysed in $1.8 \mathrm{~mL}$ of lysis buffer (50 mM Tris at $\mathrm{pH} 7.4,500 \mathrm{mM} \mathrm{NaCl}$, $0.4 \%$ SDS, $1 \mathrm{mM}$ DTT, $2 \%$ Triton- 100 with protease inhibitors) and sonicated using a Bioruptor Pico (three cycles of $30 \mathrm{sec}$ on/ $30 \mathrm{sec}$ off; Diagenode). Sonicated lysates were diluted twice in $50 \mathrm{mM}$ Tris (pH 7.4) and cleared at 16,500g for $10 \mathrm{~min}$. Following preclearing of the lysate with $100 \mu \mathrm{L}$ of Protein A/G Dynabeads (Thermo Fischer Scientific, 10015D), biotinylated proteins were isolated by incubation with $200 \mu \mathrm{L}$ of Dynabeads (MyOne Streptavidin $\mathrm{C} 1$; Life Technologies) overnight at $4^{\circ} \mathrm{C}$. The beads were washed twice in $2 \%$ SDS, twice in wash buffer 1 [0.1\% deoxycholate, $1 \%$ Triton X-100, $500 \mathrm{mM} \mathrm{NaCl}, 1 \mathrm{mM}$ EDTA, $50 \mathrm{mM}$ 4-(2hydroxyethyl)-1-piperazineethanesulfonic acid at $\mathrm{pH} 7.5]$, twice with wash buffer $2(250 \mathrm{mM} \mathrm{LiCl}, 0.5 \%$ NP-40, $0.5 \%$ deoxycholate, $1 \mathrm{mM}$ EDTA, $10 \mathrm{mM}$ Tris at $\mathrm{pH} 8$ ), and twice with $50 \mathrm{mM}$ Tris. Beads were rinsed twice with $100 \mathrm{mM}$ ammonium bicarbonate and submitted for MS. HA-BASU-Daed pull-down was subjected to TMT labeling followed by PL-MS on a nano-ESI 
Fusion Lumos mass spectrometer (Thermo Fisher Scientific). BASU-Gasz, Armi-BASU, Zuc-BASU, and Zuc-SplitBioID pulldowns were analyzed on a Q-Exactive HF mass spectrometer (Thermo Fisher Scientific). On-bead trypsin digestion and TMT chemical isobaric labeling were performed as described (Papachristou et al. 2018). Details on MS analysis are in the Supplemental Material.

\section{Split-BioID proximity labeling and MS}

OSCs $\left(4 \times 10^{6}\right)$ were transfected with $10 \mu \mathrm{g}$ of each plasmid expressing Zuc-CBirA*-6xHis and Zuc-NBirA*-HA or $20 \mu \mathrm{g}$ of HA-ZsGreen. After $36 \mathrm{~h}$, the growth medium was supplemented overnight $(\sim 18 \mathrm{~h})$ with $50 \mathrm{mM}$ biotin. Harvesting and pull-down of biotinylated proteins were performed as stated above.

\section{CoIP from cell lysates}

S2 cells or OSCs were transfected with $3 x$ Flag- and HA-tagged constructs. After $48 \mathrm{~h}$, cells were lysed in $250 \mu \mathrm{L}$ of coIP lysis buffer (Pierce) with Complete protease inhibitors (Roche). For crosslinking experiments, cell pellets were incubated with disuccinimidyl sulfoxide at $1 \mathrm{mM}$ final concentration (diluted in PBS) for $10 \mathrm{~min}$ at room temperature and $20 \mathrm{~min}$ at $4{ }^{\circ} \mathrm{C}$ followed by lysis in $50 \mathrm{mM}$ Tris (pH 7.4), $500 \mathrm{mM} \mathrm{NaCl}, 0.4 \%$ SDS, $1 \mathrm{mM}$ dithiothreitol, and $2 \%$ Triton- 100 with protease inhibitors and sonication using a Bioruptor Pico (three cycles for $30 \mathrm{sec}$ on/30 sec off; Diagenode). Two-hundred micrograms of proteins for each sample was diluted to $1 \mathrm{~mL}$ with coIP lysis buffer and incubated with $30 \mu \mathrm{L}$ of anti-Flag M2 magnetic beads (Sigma, M8823) for $2 \mathrm{~h}$ at $4^{\circ} \mathrm{C}$. The beads were washed three times for $15 \mathrm{~min}$ in TBS with protease inhibitors, resuspended in $2 \times$ NuPAGE LDS sample buffer (Thermo Fisher Scientific), and boiled for $3 \mathrm{~min}$ at $90^{\circ} \mathrm{C}$ to elute immunoprecipitated proteins.

\section{Western blot}

Images were acquired on an Odyssey CLx scanner (LiCor) using secondary antibodies (and/or streptavidin; LiCor, 925-32230) conjugated to infrared dyes from LiCor. The following primary antibodies were used: anti-HA (ab9110), anti-Flag (Sigma, F1804), anti-Piwi (Brennecke et al. 2007), anti-Atp5a (ab14748), and anti-Tubulin (ab18251).

\section{OSC immunostaining}

Cells were plated $1 \mathrm{~d}$ in advance on fibronectin-coated coverslips, fixed for $15 \mathrm{~min}$ in $4 \%$ PFA, permeabilized for $10 \mathrm{~min}$ in PBS and $0.2 \%$ Triton, and blocked for $30 \mathrm{~min}$ in PBS, $0.1 \%$ Tween- 20 (PBST), and 1\% BSA. Primary antibodies were diluted 1:500 in PBST and $0.1 \%$ BSA and incubated overnight at $4^{\circ} \mathrm{C}$. After three 5 -min washes in PBST, secondary antibodies were incubated for 1 $\mathrm{h}$ at room temperature. After three 5-min washes in PBST, DAPI was incubated for $10 \mathrm{~min}$ at room temperature and washed twice in PBST. Coverslips were mounted with ProLong Diamond antifade mountant (Thermo Fisher Scientific, P36961) and imaged on a Leica SP8 confocal microscope (100x oil objective).

For STED, the same protocol was used with the following modifications: Cells were plated on fibronectin-coated $1.5 \mathrm{H}$ coverslips, and blocking was for $1.5 \mathrm{~h}$ in PBS, $0.1 \%$ Tween-20 (PBST), and $1 \%$ BSA. Primary and secondary antibodies were diluted 1:150 in PBST and 1\% BSA. Coverslips were mounted using ProLong Glass antifade mountant (Thermo Fisher Scientific, P36982) and imaged on a Leica SP8 confocal microscope (100× oil objective). The images were deconvoluted using Huygens Professional.
The following antibodies were used: anti-GFP (ab13970), antiAtp5a (ab14748), anti-Piwi (Brennecke et al. 2007), anti-Flag (Cell Signaling Technology 14793S), anti-HA tag (ab9111), and anti-Armi (Saito et al. 2010).

\section{RNA isolation and $q P C R$ analysis}

Samples were lysed in $1 \mathrm{~mL}$ of Trizol, and RNA was extracted according to the manufacturer's instruction. One microgram of total RNA was treated with DNase I (Thermo Fisher Scientific) and reverse-transcribed with the SuperScript III first strand synthesis kit (Thermo Fisher Scientific) using oligo/dT) $\left.\right|_{20}$ primers. Real-time PCR (qPCR) experiments were performed with a QuantStudio real-time PCR LightCycler (Thermo Fisher Scientific). Transposon levels were quantified using the $\Delta \Delta \mathrm{CT}$ method (Livak and Schmittgen 2001) and normalized to $r p 49$, and fold changes were calculated relative to the indicated controls. All oligonucleotide sequences are in Supplemental Table S6.

\section{Fly stocks and handling}

All flies were kept at $25^{\circ} \mathrm{C}$ on standard cornmeal or propionic food. Flies carrying a BAC transgene expressing GFP-Gasz were generated by the Brennecke laboratory (Vienna Drosophila Resource Center, JB313277) (Handler et al. 2013). GFP-Zuc and GFP-CG10880 overexpression lines, shRNA-daed and daed mutant alleles $\left(C G 10880^{\Delta 2^{*}}\right.$ and CG10880 oof1 $)$, and the gasz mutant allele (gasz ${ }^{K O}$ ) were generated for this study (see below). Control $w^{1118}$ flies were a gift from the University of Cambridge Department of Genetics Fly Facility. For germline knockdown, we used a stock containing a UAS::Dcr2 transgene and a nos::GAL4 driver (Czech et al. 2013) and shRNA lines from the Bloomington Drosophila Stock Center (BL35227) and Vienna Drosophila Resource Center (JB313133). The fertility of mutant females was scored by crossing 10 freshly hatched females to five $w^{1118}$ males and counting the number of eggs laid in 12 -h periods and pupae that developed after $7 \mathrm{~d}$.

\section{Generation of mutant and transgenic fly strains}

Frameshift mutant alleles of daed were generated by injecting pCFD4 (Addgene plasmid, 49411) (Port et al. 2014) containing two gRNAs against CG10880 into embryos expressing vas-Cas9 (Bloomington stock, 51323). The gasz ${ }^{K O}$ allele was generated by injecting a plasmid containing two gRNAs against gasz and a donor construct with 1-kb homology arms flanking a 3xP3-RFP cassette into vas-Cas9 flies. shRNAs against daed were cloned into pVALIUM20 (Ni et al. 2011), and GFP-Daed and GFP-Zuc were cloned in an in-house generated transgenesis vector for ФC31-mediated integration and expressed under the Drosophila melanogaster ubiquitin promoter (pUBI). All plasmids were integrated into attP40 sites on chromosome 2 (stock 13-20). Microinjection and fly stock generation were carried out by the University of Cambridge Department of Genetics Fly Facility. Mutant flies were identified by genotyping PCRs and confirmed by Sanger sequencing.

\section{Ovary immunostaining}

Fly ovaries were dissected in ice-cold PBS, fixed for $15 \mathrm{~min}$ in $4 \%$ PFA at room temperature, and permeabilized with three 10-min washes in PBS with $0.3 \%$ Triton (PBS-Tr). Samples were blocked in PBS-Tr with $1 \%$ BSA for $2 \mathrm{~h}$ at room temperature and incubated overnight at $4{ }^{\circ} \mathrm{C}$ with primary antibodies in PBS-Tr and $1 \%$ BSA. After three 10-min washes at room temperature in PBS-Tr, 
secondary antibodies were incubated overnight at $4^{\circ} \mathrm{C}$ in PBS- $\mathrm{Tr}$ and $1 \%$ BSA. After four 10-min washes in PBS-Tr at room temperature (DAPI was added during the third wash) and two 5-min washes in PBS, samples were mounted with ProLong Diamond antifade mountant (Thermo Fisher Scientific, P36961) and imaged on a Leica SP8 confocal microscope. Images were deconvoluted using Huygens Professional. The following antibodies were used: anti-GFP (ab13970), anti-Atp5a (ab14748), anti-Piwi (Brennecke et al. 2007), anti-Aub (Senti et al. 2015), anti-Ago3 (Senti et al. 2015), and anti-Armi (Saito et al. 2010).

\section{CLIP-seq}

OSCs $\left(1 \times 10^{7}\right)$ were nucleofected first with $2 \mu \mathrm{L}$ of siRNA only and, $48 \mathrm{~h}$ later, with $2 \mu \mathrm{L}$ of siRNA and $5 \mu \mathrm{g}$ of the desired plasmid. Ninety-six hours later, cells were cross-linked on ice with $150 \mathrm{~mJ} / \mathrm{cm}^{2}$ at $254 \mathrm{~nm}$. Cell pellets were lysed in $300 \mu \mathrm{L}$ of lysis buffer $(50 \mathrm{mM}$ Tris- $\mathrm{HCl}$ at $\mathrm{pH} 7.5,150 \mathrm{mM} \mathrm{NaCl}, 1 \%$ Triton $\mathrm{X}$ $100,0.1 \%$ deoxycholate, protease inhibitor, RNasin Plus [1:500; Promega]), diluted to a final concentration of $\sim 1 \mu \mathrm{g} / \mu \mathrm{L}$ with 100 $\mathrm{mM}$ Tris- $\mathrm{HCl}(\mathrm{pH} 7.5)$ and $150 \mathrm{mM} \mathrm{NaCl}$, and incubated with $200 \mu \mathrm{L}$ of Magne-HaloTag (Promega, G7282) beads overnight at $4^{\circ} \mathrm{C}$. Beads were washed twice in wash buffer A $(100 \mathrm{mM}$ Tris$\mathrm{HCl}$ at $\mathrm{pH} 7.5,150 \mathrm{mM} \mathrm{NaCl}, 0.05 \%$ Igepal CA-630), three times in wash buffer B (PBS, $500 \mathrm{mM} \mathrm{NaCl}, 0.1 \%$ Triton X-100, RNasin Plus 1:2000), and three times in PBS and $0.1 \%$ Triton X-100 and rinsed in wash buffer A. Beads were resuspended in $100 \mu \mathrm{L}$ of $1 \times$ ProTEV buffer, $1 \mathrm{mM}$ DTT, RNasin Plus (1:50), and $25 \mathrm{U}$ of ProTEV Plus protease (Promega, V6101) and incubated for $2 \mathrm{~h}$ at $30^{\circ} \mathrm{C}$. Fifteen microliters of Proteinase $\mathrm{K}$ in $300 \mu \mathrm{L}$ of PK/SDS buffer $(100 \mathrm{mM}$ Tris at $\mathrm{pH} 7.5,50 \mathrm{mM} \mathrm{NaCl}, 1 \mathrm{mM}$ EDTA, $0.2 \%$ SDS) was added to the eluate and incubated for $1 \mathrm{~h}$ at $50^{\circ} \mathrm{C}$. RNA was isolated with phenol-chloroform, and library preparation was carried out with the SMARTer Stranded RNAseq kit (Takara Bio, 634839), according to the manufacturer's instructions. CLIP-seq libraries were sequenced on an Illumina HiSeq 4000 (Illumina).

\section{Small RNA sequencing (RNA-seq) library preparation}

Small RNA libraries were generated as described previously with slight modifications (McGinn and Czech 2014). Briefly, 18- to 29nt-long small RNAs were purified by PAGE from $15 \mu \mathrm{g}$ of total RNA from ovaries or OSCs. Next, the $3^{\prime}$ adapter (containing four random nucleotides at the $5^{\prime}$ end) (Jayaprakash et al. 2011) was ligated using T4 RNA ligase 2 and truncated KQ (New England Biolabs). Following recovery of the products by PAGE purification, the $5^{\prime}$ adapter (containing four random nucleotides at the $3^{\prime}$ end) was ligated to the small RNAs using T4 RNA ligase (Ambion). Small RNAs containing both adapters were recovered by PAGE purification, reverse-transcribed, and PCR-amplified. Libraries were sequenced on an Illumina HiSeq 4000. All adapter sequences are in Supplemental Table S6.

CLIP-seq and small RNA-seq analysis

Details on sequencing analysis are in the Supplemental Material.

\section{Data availability}

Raw data from proteomics and high-throughput sequencing experiments are available on Proteomics Identifications (PRIDE) database (PXD013417, PXD013405, PXD013404, and PXD013403) and Gene Expression Omnibus (GSE129321).

\section{Acknowledgments}

We thank Martin H. Fabry for help with computational analyses. We thank the Cancer Research UK Cambridge Institute Bioinformatics, Genomics, Microscopy, and Proteomics Core Facilities for support, in particular Kamal Kishore and Fadwa Joud. We thank the University of Cambridge Department of Genetics Fly Facility for microinjection services and fly stock generation. We thank the Vienna Drosophila Resource Center and the Bloomington Stock Center for fly stocks. We thank Mikiko Siomi for OSCs and anti-Armi antibody, and Julius Brennecke for anti-Aub and anti-Ago3 antibodies. Research in the Hannon laboratory is supported by Cancer Research UK and a Wellcome Trust Investigator award $(110161 / Z / 15 / Z)$. M.M. is supported by a Boehringer Ingelheim Fonds PhD fellowship.

Author contributions: M.M. performed all experiments with help from V.M., F.A.F., and B.C. A.S. analyzed the proteomics data. E.L.E. generated daed mutant flies and shRNA lines, and E.K. contributed to the characterization of their phenotype. J.W.E.S. generated gasz mutant flies. M.M., B.C., and G.J.H. designed the experiments, analyzed and interpreted the data, and wrote the manuscript with input from the other authors.

\section{Note added in proof}

While this paper was in revision, the Zamore laboratory /Ge et al. 2019) reported that Armi couples piRNA amplification in nuage to phased piRNA production on mitochondria, and a report by the Siomi laboratory (Ishizu et al. 2019) showed that Armi selectively binds to piRNA precursors and is involved in Zuc-dependent phased piRNA biogenesis.

\section{References}

Brennecke J, Aravin AA, Stark A, Dus M, Kellis M, Sachidanandam R, Hannon GJ. 2007. Discrete small RNA-generating loci as master regulators of transposon activity in Drosophila. Cell 128: 1089-1103. doi:10.1016/j.cell.2007.01.043

Czech B, Preall JB, McGinn J, Hannon GJ. 2013. A transcriptomewide RNAi screen in the Drosophila ovary reveals factors of the germline piRNA pathway. Mol Cell 50: 749-761. doi:10 .1016/j.molcel.2013.04.007

Czech B, Munafò M, Ciabrelli F, Eastwood EL, Fabry MH, Kneuss E, Hannon GJ. 2018. piRNA-guided genome defense: from biogenesis to silencing. Annu Rev Genet 52: 131-157. doi:10 .1146/annurev-genet-120417-031441

Gainetdinov I, Colpan C, Arif A, Cecchini K, Zamore PD. 2018. A single mechanism of biogenesis, initiated and directed by PIWI proteins, explains piRNA production in most animals. Mol Cell 71: 775-790.e5. doi:10.1016/j.molcel.2018.08.007

Ge DT, Wang W, Tipping C, Gainetdinov I, Weng Z, Zamore PD. 2019. The RNA-binding ATPase, Armitage, couples piRNA amplification in nuage to phased piRNA production on mitochondria. Mol Cell doi:10.1016/j.molcel.2019.04.006

Gunawardane LS, Saito K, Nishida KM, Miyoshi K, Kawamura Y, Nagami T, Siomi H, Siomi MC. 2007. A slicer-mediated mechanism for repeat-associated siRNA $5^{\prime}$ end formation in Drosophila. Science 315: 1587-1590. doi:10.1126/science .1140494

Han BW, Wang W, Li C, Weng Z, Zamore PD. 2015. Noncoding RNA. piRNA-guided transposon cleavage initiates Zucchinidependent, phased piRNA production. Science 348: 817821. doi:10.1126/science.aaa1264 
Handler D, Meixner K, Pizka M, Lauss K, Schmied C, Gruber FS, Brennecke J. 2013. The genetic makeup of the Drosophila piRNA pathway. Mol Cell 50: 762-777. doi:10.1016/j.molcel .2013.04.031

Hayashi R, Schnabl J, Handler D, Mohn F, Ameres SL, Brennecke J. 2016. Genetic and mechanistic diversity of piRNA 3'-end formation. Nature 539: 588-592. doi:10.1038/nature20162

Homolka D, Pandey RR, Goriaux C, Brasset E, Vaury C, Sachidanandam R, Fauvarque MO, Pillai RS. 2015. PIWI slicing and RNA elements in precursors instruct directional primary piRNA biogenesis. Cell Rep 12: 418-428. doi:10.1016/j.celrep .2015.06.030

Honda S, Kirino Y, Maragkakis M, Alexiou P, Ohtaki A, Murali R, Mourelatos Z, Kirino Y. 2013. Mitochondrial protein BmPAPI modulates the length of mature piRNAs. RNA 19: 1405-1418. doi:10.1261/rna.040428.113

Ipsaro JJ, Haase AD, Knott SR, Joshua-Tor L, Hannon GJ. 2012. The structural biochemistry of Zucchini implicates it as a nuclease in piRNA biogenesis. Nature 491: 279-283. doi:10 $.1038 /$ nature 11502

Ishizu H, Kinoshita T, Hirakata S, Komatsuzaki C, Siomi MC. 2019. Distinct and collaborative functions of $\mathrm{Yb}$ and Armitage in transposon-targeting piRNA biogenesis. Cell Rep 27: 18221835.e8. doi:10.1016/j.celrep.2019.04.029

Jayaprakash AD, Jabado O, Brown BD, Sachidanandam R. 2011. Identification and remediation of biases in the activity of RNA ligases in small-RNA deep sequencing. Nucleic Acids Res 39: e141. doi:10.1093/nar/gkr693

Kim DI, Jensen SC, Noble KA, Kc B, Roux KH, Motamedchaboki K, Roux KJ. 2016. An improved smaller biotin ligase for BioID proximity labeling. Mol Biol Cell 27: 1188-1196. doi:10.1091/ mbc.E15-12-0844

Le Thomas A, Rogers AK, Webster A, Marinov GK, Liao SE, Perkins EM, Hur JK, Aravin AA, Toth KF. 2013. Piwi induces piRNA-guided transcriptional silencing and establishment of a repressive chromatin state. Genes Dev 27: 390-399. doi:10 $.1101 /$ gad.209841.112

Lim AK, Kai T. 2007. Unique germ-line organelle, nuage, functions to repress selfish genetic elements in Drosophila melanogaster. Proc Natl Acad Sci 104: 6714-6719. doi:10.1073/ pnas.0701920104

Liu L, Qi H, Wang J, Lin H. 2011. PAPI, a novel TUDOR-domain protein, complexes with AGO3, ME31B and TRAL in the nuage to silence transposition. Development 138: 18631873. doi:10.1242/dev.059287

Livak KJ, Schmittgen TD. 2001. Analysis of relative gene expression data using real-time quantitative PCR and the $2^{-\Delta \Delta C(T)}$ method. Methods 25: 402-408. doi:10.1006/meth.2001.1262

Malone CD, Brennecke J, Dus M, Stark A, McCombie WR, Sachidanandam R, Hannon GJ. 2009. Specialized piRNA pathways act in germline and somatic tissues of the Drosophila ovary. Cell 137: 522-535. doi:10.1016/j.cell.2009.03.040

McGinn J, Czech B. 2014. Small RNA library construction for high-throughput sequencing. Methods Mol Biol 1093: 195208. doi:10.1007/978-1-62703-694-8_16

Mohn F, Handler D, Brennecke J. 2015. Noncoding RNA. piRNAguided slicing specifies transcripts for Zucchini-dependent, phased piRNA biogenesis. Science 348: 812-817. doi:10 $.1126 /$ science.aaa1039

Muerdter F, Guzzardo PM, Gillis J, Luo Y, Yu Y, Chen C, Fekete R, Hannon GJ. 2013. A genome-wide RNAi screen draws a genetic framework for transposon control and primary piRNA biogenesis in Drosophila. Mol Cell 50: 736-748. doi:10.1016/ j.molcel.2013.04.006
Murota Y, Ishizu H, Nakagawa S, Iwasaki YW, Shibata S, Kamatani MK, Saito K, Okano H, Siomi H, Siomi MC. 2014. Yb integrates piRNA intermediates and processing factors into perinuclear bodies to enhance piRISC assembly. Cell Rep 8: 103-113. doi:10.1016/j.celrep.2014.05.043

Ni JQ, Zhou R, Czech B, Liu LP, Holderbaum L, Yang-Zhou D, Shim HS, Tao R, Handler D, Karpowicz P, et al. 2011. A genome-scale shRNA resource for transgenic RNAi in Drosophila. Nat Methods 8: 405-407. doi:10.1038/nmeth.1592

Niki Y, Yamaguchi T, Mahowald AP. 2006. Establishment of stable cell lines of Drosophila germ-line stem cells. Proc Natl Acad Sci 103: 16325-16330. doi:10.1073/pnas.0607435103

Nishida KM, Sakakibara K, Iwasaki YW, Yamada H, Murakami R, Murota Y, Kawamura T, Kodama T, Siomi H, Siomi MC. 2018. Hierarchical roles of mitochondrial Papi and Zucchini in Bombyx germline piRNA biogenesis. Nature 555: 260-264. doi:10.1038/nature25788

Nishimasu H, Ishizu H, Saito K, Fukuhara S, Kamatani MK, Bonnefond L, Matsumoto N, Nishizawa T, Nakanaga K, Aoki J, et al. 2012. Structure and function of Zucchini endoribonuclease in piRNA biogenesis. Nature 491: 284-287. doi:10 $.1038 /$ nature 11509

Olivieri D, Sykora MM, Sachidanandam R, Mechtler K, Brennecke J. 2010. An in vivo RNAi assay identifies major genetic and cellular requirements for primary piRNA biogenesis in Drosophila. EMBO I 29: 3301-3317. doi:10.1038/emboj.2010 .212

Olivieri D, Senti KA, Subramanian S, Sachidanandam R, Brennecke J. 2012. The cochaperone shutdown defines a group of biogenesis factors essential for all piRNA populations in Drosophila. Mol Cell 47: 954-969. doi:10.1016/j.molcel.2012.07 .021

Ozata DM, Gainetdinov I, Zoch A, O'Carroll D, Zamore PD. 2019. PIWI-interacting RNAs: small RNAs with big functions. Nat Rev Genet 20: 89-108. doi:10.1038/s41576-018-0073-3

Pandey RR, Homolka D, Chen KM, Sachidanandam R, Fauvarque MO, Pillai RS. 2017. Recruitment of Armitage and Yb to a transcript triggers its phased processing into primary piRNAs in Drosophila ovaries. PLoS Genet 13: e1006956. doi:10.1371/ journal.pgen.1006956

Papachristou EK, Kishore K, Holding AN, Harvey K, Roumeliotis TI, Chilamakuri CSR, Omarjee S, Chia KM, Swarbrick A, Lim E, et al. 2018. A quantitative mass spectrometry-based approach to monitor the dynamics of endogenous chromatin-associated protein complexes. Nat Commun 9: 2311. doi:10 .1038/s41467-018-04619-5

Port F, Chen HM, Lee T, Bullock SL. 2014. Optimized CRISPR/ Cas tools for efficient germline and somatic genome engineering in Drosophila. Proc Natl Acad Sci 111: E2967-E2976. doi:10.1073/pnas.1405500111

Qi H, Watanabe T, Ku HY, Liu N, Zhong M, Lin H. 2011. The Yb body, a major site for Piwi-associated RNA biogenesis and a gateway for Piwi expression and transport to the nucleus in somatic cells. J Biol Chem 286: 3789-3797. doi:10.1074/jbc .M110.193888

Ramanathan M, Majzoub K, Rao DS, Neela PH, Zarnegar BJ, Mondal S, Roth JG, Gai H, Kovalski JR, Siprashvili Z, et al. 2018. RNA-protein interaction detection in living cells. Nat Methods 15: 207-212. doi:10.1038/nmeth.4601

Rogers AK, Situ K, Perkins EM, Toth KF. 2017. Zucchini-dependent piRNA processing is triggered by recruitment to the cytoplasmic processing machinery. Genes Dev 31: 1858-1869. doi:10.1101/gad.303214.117

Roux KJ, Kim DI, Raida M, Burke B. 2012. A promiscuous biotin ligase fusion protein identifies proximal and interacting 
proteins in mammalian cells. J Cell Biol 196: 801-810. doi:10 $.1083 /$ jcb. 201112098

Rozhkov NV, Hammell M, Hannon G). 2013. Multiple roles for Piwi in silencing Drosophila transposons. Genes Dev 27: 400-412. doi:10.1101/gad.209767.112

Saito K. 2014. RNAi and overexpression of genes in ovarian somatic cells. Methods Mol Biol 1093: 25-33. doi:10.1007/ 978-1-62703-694-8_3

Saito K, Inagaki S, Mituyama T, Kawamura Y, Ono Y, Sakota E, Kotani H, Asai K, Siomi H, Siomi MC. 2009. A regulatory circuit for piwi by the large Maf gene traffic jam in Drosophila. Nature 461: 1296-1299. doi:10.1038/nature08501

Saito K, Ishizu H, Komai M, Kotani H, Kawamura Y, Nishida KM, Siomi H, Siomi MC. 2010. Roles for the Yb body components Armitage and $\mathrm{Yb}$ in primary piRNA biogenesis in Drosophila. Genes Dev 24: 2493-2498. doi:10.1101/gad.1989510

Schopp IM, Amaya Ramirez CC, Debeljak J, Kreibich E, Skribbe M, Wild K, Béthune J. 2017. Split-BioID a conditional proteomics approach to monitor the composition of spatiotemporally defined protein complexes. Nat Commun 8: 15690. doi: $10.1038 /$ ncomms 15690

Senti KA, Jurczak D, Sachidanandam R, Brennecke J. 2015. piRNA-guided slicing of transposon transcripts enforces their transcriptional silencing via specifying the nuclear piRNA repertoire. Genes Dev 29: 1747-1762. doi:10.1101/gad .267252 .115

Sienski G, Dönertas D, Brennecke J. 2012. Transcriptional silencing of transposons by Piwi and maelstrom and its impact on chromatin state and gene expression. Cell 151: 964-980. doi:10.1016/j.cell.2012.10.040

Szakmary A, Reedy M, Qi H, Lin H. 2009. The Yb protein defines a novel organelle and regulates male germline stem cell selfrenewal in Drosophila melanogaster. I Cell Biol 185: 613627. doi:10.1083/jcb.200903034

Vagin VV, Yu Y, Jankowska A, Luo Y, Wasik KA, Malone CD, Harrison E, Rosebrock A, Wakimoto BT, Fagegaltier D, et al. 2013. Minotaur is critical for primary piRNA biogenesis. RNA 19: 1064-1077. doi:10.1261/rna.039669.113

Vourekas A, Zheng K, Fu Q, Maragkakis M, Alexiou P, Ma J, Pillai RS, Mourelatos Z, Wang PJ. 2015. The RNA helicase MOV10L1 binds piRNA precursors to initiate piRNA processing. Genes Dev 29: 617-629. doi:10.1101/gad.254631.114

Wang SH, Elgin SC. 2011. Drosophila Piwi functions downstream of piRNA production mediating a chromatin-based transposon silencing mechanism in female germ line. Proc Natl Acad Sci 108: 21164-21169. doi:10.1073/pnas .1107892109

Wang W, Han BW, Tipping C, Ge DT, Zhang Z, Weng Z, Zamore PD. 2015. Slicing and binding by Ago3 or Aub trigger Piwibound piRNA production by distinct mechanisms. Mol Cell 59: 819-830. doi:10.1016/j.molcel.2015.08.007

Zhang J, Wang Q, Wang M, Jiang M, Wang Y, Sun Y, Wang J, Xie T, Tang C, Tang N, et al. 2016. GASZ and mitofusin-mediated mitochondrial functions are crucial for spermatogenesis. EMBO Rep 17: 220-234. doi:10.15252/embr.201540846 


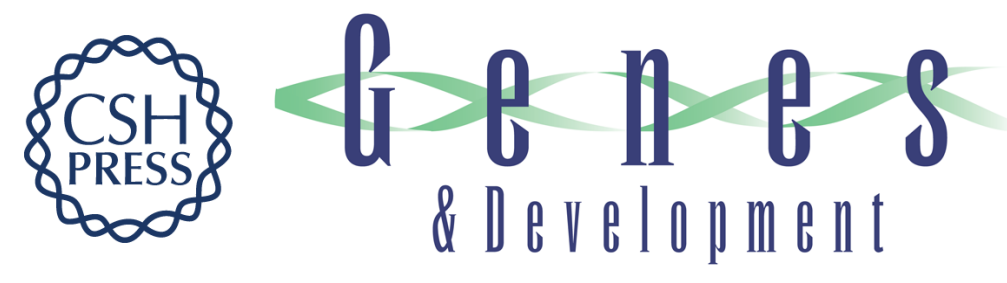

\title{
Daedalus and Gasz recruit Armitage to mitochondria, bringing piRNA precursors to the biogenesis machinery
}

\author{
Marzia Munafò, Vera Manelli, Federica A. Falconio, et al.
}

Genes Dev. 2019, 33: originally published online May 23, 2019

Access the most recent version at doi:10.1101/gad.325662.119

\section{Supplemental http://genesdev.cshlp.org/content/suppl/2019/05/20/gad.325662.119.DC1 Material}

References This article cites 51 articles, 21 of which can be accessed free at: http://genesdev.cshlp.org/content/33/13-14/844.full.html\#ref-list-1

Creative This article, published in Genes \& Development, is available under a Creative Commons Commons License (Attribution 4.0 International), as described at License http://creativecommons.org/licenses/by/4.0/.

Email Alerting Receive free email alerts when new articles cite this article - sign up in the box at the top Service right corner of the article or click here.

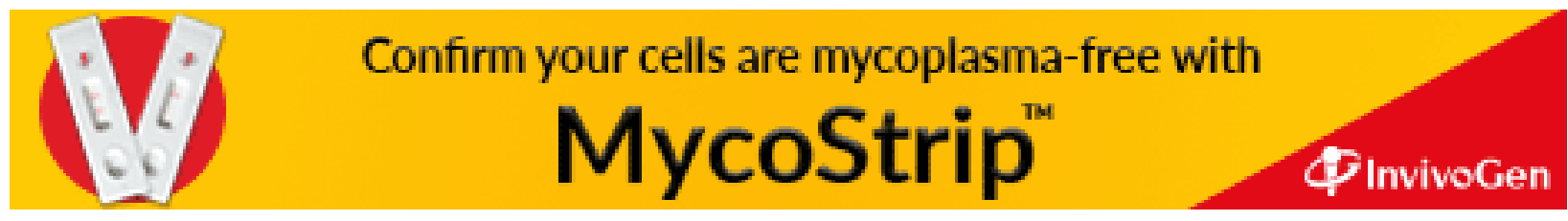

